done on the first patient-the signs were insidious in onset and the diagnosis was not at first suspected. A third patient died as a result of rupture of the spleen and jejunum, avulsion of the small-bowel mesentery, and gangrene of lower small-bowel segments. The first patient was wearing the simple lap type of seat belt, and, though it is not specified, it seems likely that the same pattern was used by the other two victims.

Similar injuries, also partly attributed to seat belts, have been reported before, though they are rare. Damage to the liver, pancreas, abdominal aorta, and lumbar spine have also been described. It is certainly right to draw attention to these lesions, so that casualty surgeons are aware of the possibility and are on the lookout for them. Most such injuries have resulted from the use of the lap type of belt, which seems to give little protection against the forcible forward flexion and resultant acute compression of the abdomen which occur on impact. Considerable shearing forces can be exerted between the lumbar spine and the belt, and greatly increased intraluminal pressure within temporarily closed loops of bowel may cause perforation. While major haemorrhage within the abdomen is likely to show clinical signs soon after the accident, the signs of perforation of the bowel may take hours or even days to become apparent.

How should these isolated reports affect our general policy towards the use of seat belts in cars ? It is impossible to subject the questions concerned to controlled trial, and there is no way of knowing what would have happened to the victims reported as sustaining injury from the seat belts if they had not been wearing them. We have to look at these particular injuries against larger questions. Which are the most frequent fatal injuries sustained in traffic accidents, and do seat belts significantly diminish the mortality risks of these injuries ? The evidence that they save lives is indeed impressive. In Britain W. Gissane ${ }^{2}$ in 1963 reviewed approximately 12,000 victims of road traffic accidents and concluded that there was not one in whom it was clear that the wearing of a seat belt had caused or exacerbated the injury. A recent editorial in the Medical fournal of Australia $^{3}$ remarked on the seriousness and high mortality rate of ejection injuries, most of which could be completely prevented by the wearing of an adequate belt. Also from Australia $^{4}$ came an analysis of 114 patients who sustained major facial injuries in car accidents; only one had worn a belt at the time of the accident. Comprehensive inquiries into large series of car accidents both in California ${ }^{5}$ and in New York ${ }^{6}$ have shown a decrease in mortality of up to $35 \%$ when comparing those wearing seat belts with those without. It is also of interest from the North American studies that intra-abdominal injuries were of similar frequency in those without seat belts as in those with them.

Only in one type of accident, in which the occupants of a car are crushed, is there no gain to be derived from the wearing of a seat belt, but fortunately such accidents constitute a very small minority. Neither the slight possibility of this particular type of accident nor the extremely remote possibility of injury from the belt itself should in any way diminish the campaigns to have safety belts fitted-and,

1 Porter, S. D., and Green, E. W., Arch. Surg., 1968, 96, 242.

2 Gi isane. W.. Lancet, 1963, 2, 695.

- Med. 7. Aust., 1967, 1, 345.

- Hueston. J. T., Cook, R. M., and Langford, A., Med. F. Aust., 1964, 1, 940.

s Tourin, B., and Garrett, J. W.. in Automative Crash Injury Research, 1960. Cornell University, New York.

- Garrett, J. W., and Braunstein, P W., f. Trauma, 1962, 2, 220 what is far more important, constantly used. The evidence from the very few injuries which may be causally related to the belts again indicates the distinct superiority of a diagonal or lap-and-diagonal appliance which prevents sudden acute flexion of the trunk. Furthermore from several of the reports it is clear that belts may have been too loosely applied. It is important to ensure that the belt fits snugly enough to give secure support.

\section{Cancer and Sex Chromosomes}

The only clear example in man of a direct association between a specific chromosomal abnormality and a neoplastic state is the presence of the Philadelphia chromosome in cases of chronic granulocytic leukaemia. There are also several examples of association between chromosomal abnormality and increased predisposition to cancer-the best known is the increased risk of leukaemia in Down's syndrome (mongolism), in which there is an extra chromosome 21 . The registration of individuals with congenital chromosomal abnormalities may well lead to the discovery of further such associations.

When there is more than one $\mathbf{X}$ chromosome in a cell the second (and subsequent) appear in histological preparations as darkly stained aggregates of chromatin within the nucleus. So assessment of sex chromatin is relatively easy, and may be used to study possible relationships between abnormalities of the sex chromosomes and cancer. Thus J. Teter and R. Tarlowski ${ }^{1}$ found four gonadal neoplasms in 13 patients with Turner's syndrome-significantly more than would be expected.

V. M. Kimel ${ }^{2}$ reported that cancers of the breast, unlike other cancers in women, may show a sex-chromatin count (that is, percentage of cells containing an identifiable sex chromatin mass) different from that in normal female tissues. In addition, he presented evidence that tumours in which the average sex chromatin count was within the normal range tended to be oestrogen-dependent, while those with low sex chromatin counts were not, but, on the other hand, were less prone to metastasize. A. Bohle and his colleagues ${ }^{3}$ summarized 10 reports from the German literature on studies of sex chromatin in cases of breast cancer. Like Kimel, they concluded that low sex chromatin (that is, male) counts are associated with lowered responsiveness to hormones. But, unlike Kimel, they considered the low sex chromatin tumours to be the more malignant.

R. L. Shirley ${ }^{4}$ recently reported a retrospective study of 89 patients with metastatic breast cancer from the records of the Massachusetts General Hospital. The extent of the response of these patients to various treatments affecting hormonal balance was recorded in the notes. Shirley examined the pathological specimens to discover the proportion of cells with sex chromatin bodies. The results of his study suggest that a trial of hormonal treatment is more likely to be successful for tumours with relatively normal sex chromatin counts than for tumours which have markedly abnormal counts. In particular, response to hormones is likely to be

1 Teter, J., and Tarlnwski, R., Amer. F. Obstet. Gynec., 1960, 79, 321.

2 Kimel, V. M., Cancer (Philud.), 1957, 10, 922.

3 Bohle, A., Bürger, E., Fischbach, H., and Schooli-Tubingen, A., Langenbecks Arch. Klin. Chir., 1965, 313, 392.

4 Shirley, R. L., Surg. Gynec. Obstet., 1967, 125, 737.

5 Atkin, N. B., Wien. klin. W schr., 1964, 76, 859.

Atkin, N. B., Brit. f. Cancer, 1967, 21, 40.

Atkin, N. B., Lancet, 1967, 2, 1145. 
poor in young women with high counts and in older women with low counts.

It is by no means clear that abnormalities in sex chromatin are causally related to responsiveness to hormones. Indeed, it is just as likely that the changes are non-specific and are secondary to the malignant change. According to N. B. Atkin $^{5-7}$ the production of supernumerary $\mathrm{X}$ chromosomes in tumours tends to be correlated directly with ploidy level-the number of sets of chromosomes in the cell. In a study of 278 squamous-cell tumours of the cervix uteri and 104 carcinomas of the corpus uteri he found no correlation between the presence or absence of sex chromatin and histological grade.

Whether the sex chromatin complement is a specific or non-specific marker of hormone sensitivity of breast cancers is of less importance than knowing which form of hormone therapy is most likely to be successful. It is to be hoped that future studies of the amount of sex chromatin in cells and of the proportion of cells with identifiable sex chromatin bodies -and indeed of other variables in breast tumours or in the patients who bear them-will enable accurate prediction of the most suitable form of therapy.

\section{Alcoholic Myopathy}

To the already numerous recognized complications of alcoholism, R. Hed and his colleagues in 1955 added yet another -an acute, reversible myopathic syndrome. This occurs in chronic alcoholics after a period of particularly high intake, and may be associated with myoglobinuria. ${ }^{1-2}$ Subsequently a further syndrome was described in these subjects, characterized by the insidious development of proximal weakness and wasting in the limbs. ${ }^{3}$ The detailed features of both the acute and the chronic syndromes and their relationships have recently been studied by G. T. Perkoff and his associates, ${ }^{4-6}$ and by others. ${ }^{78}$

Patients with the acute syndrome complain of severe muscular aching and tenderness, which is often accompanied by cramps. Weakness is present, but may be difficult to demonstrate because of pain; other features include oedema of the muscles and subcutaneous tissues. The wcakness usually recovers when the patient stops drinking alcohol. Sometimes, however, it persists, leading to a syndrome resembling chronic alcoholic myopathy. Electromyography shows myopathic abnormalities, and the levels in the serum of enzymes derived from muscle, such as creatine kinase, are raised. Histologically biopsy specimens of muscle show degeneration and necrosis of the fibres-a finding which explains the myoglobinuria, which results from the release of

\footnotetext{
Hed, R., Larsson, H., and Wahlgren, F., Acta med. scand., 1955, 152, 459.

Hed, R., Lundmark, C., Fahlgren, H., and Orell, S., Acta med. scand., 1962, 171, 58:

" Ekbom, K., Hed., R., Kirstein, L., and Aström, K., Arch. Neurol. (Chic.), 1964, 10, 449.

- Perkoff, G. T., Hardy, P., and Velez-Garcia, E., New Engl. 7. Med. 1966, 274, 1277

"Perkoff, G. T., Dioso, M M., Bleisch, V., and Klinkerfuss, G., Ann. intern. Med., 1967, 67, 481.

Klinkereuss, G., Bleisch, V.. Dioso, M. M., and Perkoff, G. T., Ann intern. Med., 1967, 67, 493.

Serratrice, G., Toga, M., and Roux, H., Presse méd., 1966, 74, 1721

- Douglas, R. M., Fewings, J. D., Casley-Smith, J. R., and West, R. F., Aust. Ann. Med., 1966, 15, 251.

- Vel z-Garcia, E., Hardy, P., Dioso, M., and Perkoff. G. T., F. Lab. clin. Med., 1966, 68, 636 .
}

myoglobin from the muscle fibres. Electron-microscope studies have demonstrated that there is severe intracellular oedema, with destruction of mitochondria and myofilaments.

In these subjects the rise in blood lactate after ischaemic exercise has been found to be less than usual, ${ }^{4}$ which suggests that the breakdown of glycogen in the muscles is diminished. The explanation of this finding is still uncertain. Similar biochemical changes are also present in alcoholic subjects without muscle complaints other than tenderness. ${ }^{9}$ In both groups the abnormality recovers fully with abstinence.

In the chronic syndrome muscle weakness is a prominent symptom. This may be either diffuse or localized to proximal muscles, especially of the pelvic girdle and thighs, and on examination these muscles are found to be wasted and tender. The biochemical and histological abnormalities in the chronic syndrome resemble those found in the acute syndrome, but they are less striking. It seems likely, therefore, that chronic myopathy results from repeated alcoholic bouts with recurrent damage of the type observed in the more florid acute cases.

The cause of alcoholic myopathy is not yet clear. Perkoff and his associates ${ }^{6}$ believe that the initial change is intracellular oedema, probably resulting from altered sarcolemmal permeability. The other changes may be secondary to the oedema. In support of this interpretation it has been shown that alcohol can influence the transport of inorganic ions across many types of cell membrane, including the sarcolemma.

\section{B.M.A. at the Seaside}

Leaden skies, strong winds, and almost constant rain are features of the cartoonist's English seaside summer; but the B.M.A. was a little unlucky to find this weather in June at Eastbourne, which has an outstanding record for sunshine. Representatives at least had the compensation of one of the best physical settings ever for an Annual Meeting-the new Congress Theatre at Eastbourne is large, airy, and comfortable and within walking distance of the official hotels.

But if Eastbourne weather disappointed the hospitality made up for it. The week's social programme was successfully launched with champagne at the Welcome Reception given jointly by the Corporation of Eastbourne and the Eastbourne Division of the B.M.A. ; while the sun made one of its brief appearances at the garden party given by the Southcastern Metropolitan Regional Hospital Board and the Eastbourne Hospitals Management Committee. The party was held in the gardens of an eighteenth-century manor house which now houses a collection of modern British paintings.

The less formal social programme catered for all tastes, from opera at Glyndebourne to the Eastbourne Fols 1968, who shared the stage of the Congress Theatre with the platform party of the B.M.A. An attractive ladies' programme, organized by Dr. Nancy Lord, was another sufferer at the hands of the weather.

The Association is much indebted to all who worked so hard to make the Meeting a success, and particular thanks are due to Dr. I. M. Brown, Chairman of the Local Organizing Committee, and to Dr. C. M. Dunlop, the General Secretary, as well as to their colleagues who assisted them. 